\title{
Effect of FIFA 11+ Training Program on Soccer-Specific Physical Performance and Functional Movement in Collegiate Male Soccer Players: A Randomized Controlled Trial
}

\author{
Juyoung Hwang ${ }^{1}$, Jooyoung Kim ${ }^{2}$ \\ ${ }^{1}$ Sports and Health Care Major, College of Humanities and Arts, Korea National University of Transportation, Chungju; ${ }^{2}$ Department of Anatomy, School of Medicine, \\ Kyungpook National University, Daegu, Korea
}

PURPOSE: This study aimed to investigate the effects of the FIFA 11+ training program on soccer-specific physical performance and functional movement of collegiate male soccer players.

METHODS: Twenty healthy male soccer players (age: $20.0 \pm 0.7$ years, height: $174.2 \pm 4.3 \mathrm{~cm}$, weight: $67.3 \pm 7.0 \mathrm{~kg}$ ) participated in this study and were randomly divided into the $11+$ training group $(n=10)$ and control group $(n=10)$. The FIFA $11+$ training program was incorporated five times a week for 12 weeks and each session took about 20-25 minutes. The control group performed a normal warmup. Participants' soccer-specific physical performance (10-m and 30-m sprint test, coordination test, arrowhead agility test, and Yo-Yo intermittent recovery test level 1 (Yo-Yo IR test level 1) and functional movement (deep squat, hurdle step, in-line lunge, shoulder mobility, straight-leg raise, trunk stability push-up, and rotary stability) were measured.

RESULTS: The results showed that the FIFA 11+ training program group showed a significant improvement in the 30-m sprint ( $p=.027)$, coordination test $(p=.021)$, and arrowhead agility test (right: $p=.009$, left: $p=.004)$, but not in the 10-m sprint and Yo-Yo IR test level 1, compared to the control group. Regarding functional movement, the FIFA 11+ training program group showed significantly better deep squat $(p=.035)$, hurdle step $(p=.005)$, rotary stability $(p=.005)$, and total FMS scores $(p=.001)$ than the control group.

CONCLUSIONS:We concluded that a 12-week FIFA 11+ training program had positive effects on soccer-specific physical performance and functional movement of collegiate male soccer players.

Key words: FIFA 11+Training Program, Functional movement, Physical performance, Soccer

\section{INTRODUCTION}

Soccer is one of the most widely enjoyed sports around the world [1]. It is characterized by intermittent high-intensity action, such as sprint and counterattacks, and low and moderate-intensity action, such as marching and jogging [2]. Modern soccer demands a high level of physical condition with faster play and more frequent pressing [3]. Thus, a soccer player's physical performance is a crucial determinant in playing a successful soccer game [4].

Although multiple training programs have been conducted to enhance players' physical performance, inappropriate training programs that did not consider players' movements actually served as a cause of injury [5,6]. Therefore, the Medical and Research Centre (F-MARC) of the International Federation of Football Associations (FIFA) conducted a joint research with the Oslo Sports Trauma Research Center and Santa Monica Orthopaedic and Sports Medicine Center to develop the 11+ training program for soccer players $[7,8]$. The $11+$ training program was developed primarily as a warm-up for injury prevention [9], but a recent study reported that this training program can enhance soccer players' physical performance [10].

In recent years, improvements in factors such as stability, mobility, core strength, balance, and proprioception after training are emphasized

Corresponding author: Jooyoung Kim Tel +82-53-420-4910 Fax +82-53-422-9195 E-mail hirase1125ahanmail.net

Received 14 May 2019 Revised 10 Apr 2019 Accepted 11 Apr 2019

(a) This is an Open Access article distributed under the terms of the Creative Commons Attribution Non-Commercial License (http://creativecommons.org/licenses/by-nc/4.0/) which permits unrestricted non-commercial use, distribution, and reproduction in any medium, provided the original work is properly cited. 
in addition to enhanced physical performance appropriate to the sport $[11,12]$. These factors play a pivotal role in maintaining or improving physical performance by enhancing movement and lowering the potential risk of injury [13-15].

The functional movement screen (FMS) is a simple method to assess these factors [16,17]. FMS is a movement assessment tool developed by Gray Cook in the United States, and it is applied in training based on multiple research findings [18,19]. FMS has three purposes: (1) identify body asymmetries, (2) assess mobility and stability within the kinetic chain of whole-body movements, and (3) detect poor-quality movement patterns [20]. A recent study reported that FMS scores are significantly associated with athletes' physical performance [21].

Most studies thus far focused on confirming that the FIFA 11+ training program is effective in preventing injury in soccer athletes $[8,9,22$ 25], but there has not been much discussion on whether it can contribute to bringing about changes in soccer athletes' physical performance or functional movement. Therefore, this study aimed to investigate the effects of the FIFA 11+ training program on soccer-specific physical performance and functional movement of collegiate male soccer players. We hypothesized that the FIFA 11+ training group and control group would differ significantly among the measured parameters, where the FIFA 11+ training group would show better soccer-specific physical performance and functional movement compared to the control group.

\section{METHODS}

\section{Subjects}

Twenty healthy male soccer players at the M University in North Gyeongsang Province (age: $20.0 \pm 0.7$ years, height: $174.2 \pm 4.3 \mathrm{~cm}$, weight: $67.3 \pm 7.0 \mathrm{~kg}$ ) were enrolled in this study. The positions of the athletes were forward, midfielder, and defender with no goalkeeper, and the mean length of their career was 7 years.

The participants had no history of musculoskeletal injury, such as shoulder, ankle, knee, or hip joint injuries in the past six months, and they did not take any dietary supplements that may have potentially affected the outcomes of this study. The satisfaction of the inclusion criteria was confirmed based on a health history questionnaire.

The participants were given a detailed explanation regarding the purpose and procedure of this study, after which they voluntarily signed an informed consent form. The participants were then randomly divided into the FIFA $11+$ training group $(n=10)$ and control group $(n=10)$. Ta- ble 1 shows the physical characteristics of each group.

\section{FIFA 11+ training program}

The FIFA 11+ training program consists of three parts: beginning

Table 1. Physical characteristics of participants

\begin{tabular}{lccc}
\hline Variable & $\begin{array}{c}\text { FIFA 11+ training } \\
\text { group }(\mathrm{n}=10)\end{array}$ & $\begin{array}{c}\text { Control group } \\
(\mathrm{n}=10)\end{array}$ & $p$ \\
\hline Age $(\mathrm{yr})$ & $20.0 \pm 0.6$ & $20.1 \pm 0.8$ & .732 \\
Height $(\mathrm{cm})$ & $173.9 \pm 4.0$ & $174.6 \pm 4.8$ & .648 \\
Body weight $(\mathrm{kg})$ & $68.0 \pm 8.3$ & $66.5 \pm 5.8$ & .532 \\
BMl $\left(\mathrm{kg} / \mathrm{m}^{2}\right)$ & $22.2 \pm 2.3$ & $21.6 \pm 1.8$ & .584 \\
Body fat $(\%)$ & $15.2 \pm 5.1$ & $14.0 \pm 2.8$ & .777 \\
\hline
\end{tabular}

Values are Mean \pm SD.

Tested by independent sample $t$-test.

$\mathrm{BMI}$, body mass index.

Table 2. Components of FIFA 11+ training program

\begin{tabular}{|c|c|}
\hline Exercise & Protocol \\
\hline \multicolumn{2}{|l|}{ Part I: Running exercise (8 minutes) } \\
\hline Running straight ahead & 2 Repetitions \\
\hline Running hip out & 2 Repetitions \\
\hline Running hip in & 2 Repetitions \\
\hline Running circling partner & 2 Repetitions \\
\hline Running shoulder contact & 2 Repetitions \\
\hline Running quick forwards and backwards & 2 Repetitions \\
\hline \multicolumn{2}{|c|}{ Part II: Strength, plyometrics, balance (10 minutes) } \\
\hline \multicolumn{2}{|l|}{ The bench } \\
\hline Level 1: static & $3 \times 20-30 \mathrm{sec}$ \\
\hline Level 2: alternate legs & $3 \times 20-30 \mathrm{sec}$ \\
\hline Level 3: one leg lift and hold & $3 \times 20-30 \mathrm{sec}$ \\
\hline \multicolumn{2}{|l|}{ Sideways bench } \\
\hline Level 1: static & $3 \times 20-30$ sec (each side) \\
\hline Level 2: raise and lower hip & $3 \times 20-30$ sec (each side) \\
\hline Level 3: with leg lift & $3 \times 20-30$ sec (each side) \\
\hline \multicolumn{2}{|l|}{ Hamstrings } \\
\hline Level 1: Beginner & 3-5 Repetitions \\
\hline Level 2: Intermediate & 7-10 Repetitions \\
\hline Level 3: Advanced & 12-15 Repetitions \\
\hline \multicolumn{2}{|l|}{ Single-leg stance } \\
\hline Level 1: hold the Ball & $2 \times 30 \mathrm{sec}$ \\
\hline Level 2: throwing ball with partner & $2 \times 30 \mathrm{sec}$ \\
\hline Level 3: test your partner & $2 \times 30 \mathrm{sec}$ \\
\hline \multicolumn{2}{|l|}{ Squats } \\
\hline Level 1: with toe raise & $2 \times 30 \mathrm{sec}$ \\
\hline Level 2: walking lunges & $2 \times 30 \mathrm{sec}$ \\
\hline Level 3: one leg squats & $2 \times 30 \mathrm{sec}$ (each leg) \\
\hline \multicolumn{2}{|l|}{ Jumping } \\
\hline Level 1: vertical jumps & $2 \times 30 \mathrm{sec}$ \\
\hline Level 2: lateral jumps & $2 \times 30 \mathrm{sec}$ \\
\hline Level 3: box jumps & $2 \times 30 \mathrm{sec}$ \\
\hline \multicolumn{2}{|l|}{ Part III: Running exercises ( 2 minutes) } \\
\hline Running across the pitch & 2 Repetitions \\
\hline Running bouding & 2 Repetitions \\
\hline Running plant and cut & 2 Repetitions \\
\hline
\end{tabular}


with running exercises (part I); followed by six exercises to develop strength, balance, muscle control, and core stability (part II); and ending with advanced running exercises (part III) [26]. Table 2 shows the details of each part.

The investigator provided a thorough explanation of each exercise to the participants using the data downloaded from the website (http:// www.footballmedicinecentre.com/11-warm-up-program) and emphasized the importance of maintaining appropriate posture and body control, such as leg alignment, knee positioning over the toes, and smooth landings during exercise [9]. To help participants familiarize themselves with the exercises, we color-printed and passed out the downloaded data. The FIFA 11+ training program was administered five times a week for 12 weeks, and each session took about 20-25 minutes [7,10,23]. Exercises included in part II were divided into four-week sessions for progressive exercise: level 1 for the first four weeks, level 2 for the next four weeks, and level 3 for the last four weeks.

The investigator set up the field for the FIFA 11+ training program in advance. Six cones were placed in 5-6 m intervals, and another row of cones were placed next to the first row. Next to the cones, there was an area prepared so all ten players could perform the movements without interfering with one another. Parts I and III were performed in the cone area and part II was performed in the separate area next to the cones. The FIFA 11+ training group performed the FIFA 11+ training in place of the usual warm-up. The control group performed the usual warm-up, which only included light running and static and dynamic stretching.

\section{Soccer-specific physical performance}

In this study, we measured the $10-\mathrm{m}$ and $30-\mathrm{m}$ sprint test, coordination test, arrowhead agility test, and Yo-Yo intermittent recovery test level 1 (Yo-Yo IR test level 1) for soccer-specific physical performance, which are the standardized parameters measured for soccer athletes registered in the Korea Football Association. The 10-m and 30-m sprint test was performed first, followed by the coordination test and arrowhead agility test, and the Yo-Yo IR test level 1 was performed after sufficient rest. The players were given a clear explanation about the measured parameters and methods of measurement. The players warmed up prior to the measurement.

Timing gates and an electronic device (Brower TC, Brower Timing Systems, Draper, Utah, USA) were used to obtain accurate measurements. Timing gates were installed at the start and finish line. Measurements were taken repeatedly prior to the study to minimize error and increase accuracy, and the same investigator took the measurements. The measurements were recorded in the investigator's electronic device. With the exception of the Yo-Yo IR test level 1, all parameters were tested twice, with a one-minute rest in between tests. The fastest record from the two tests was used as the final record.

\section{1) 10- and 30-m sprint test}

For the sprint test, the participants held the standing position $50 \mathrm{~cm}$ behind the start line and took off upon the investigator's cue [27]. They sprinted 10 and $30 \mathrm{~m}$ before passing the finish line. The $10-\mathrm{m}$ sprint test was performed first, followed by the 30-m sprint test.

\section{2) Coordination test}

The coordination test measures how well a soccer athlete controls his or her body. The test covers a distance of $22 \mathrm{~m}$, and nine cones were used. Two cones were placed at the start line. Four cones were placed from the start line in two-meter intervals. The other three cones were placed $10 \mathrm{~m}$ straight away from the fourth cone, also in two-meter intervals (Fig. 1).

The participants stood at the start line with a soccer ball and took off upon the investigator's cue. They passed the cones to reach the final cone as quickly as possible while dribbling the ball and not touching or knocking down the cones and crossed the finish line (same as the start line) in the same manner. A penalty was given (2 seconds added to the recording time) every time the player knocked down a cone, passed a cone, or did not pass the halfway point. The coordination test procedure was determined with reference to the study by Joo [28].

\section{3) Arrowhead agility test}

The arrowhead agility test is a highly reliable method used to measure

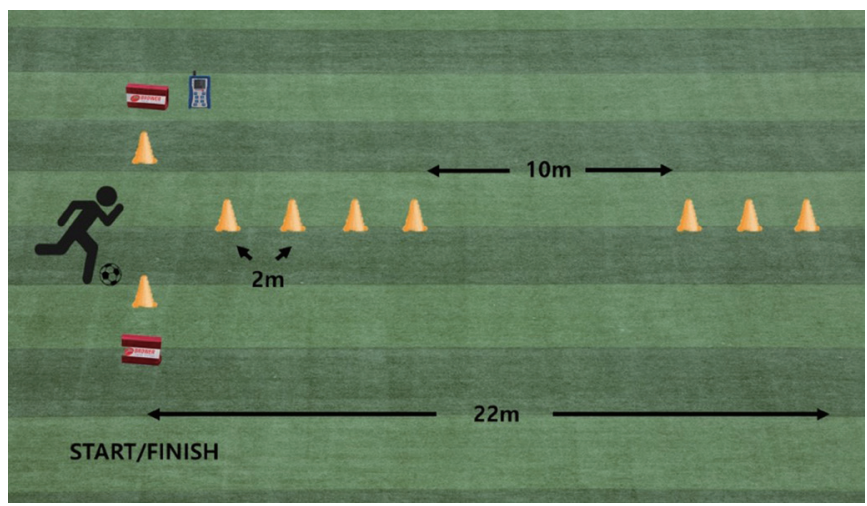

Fig. 1. Coordination test. 


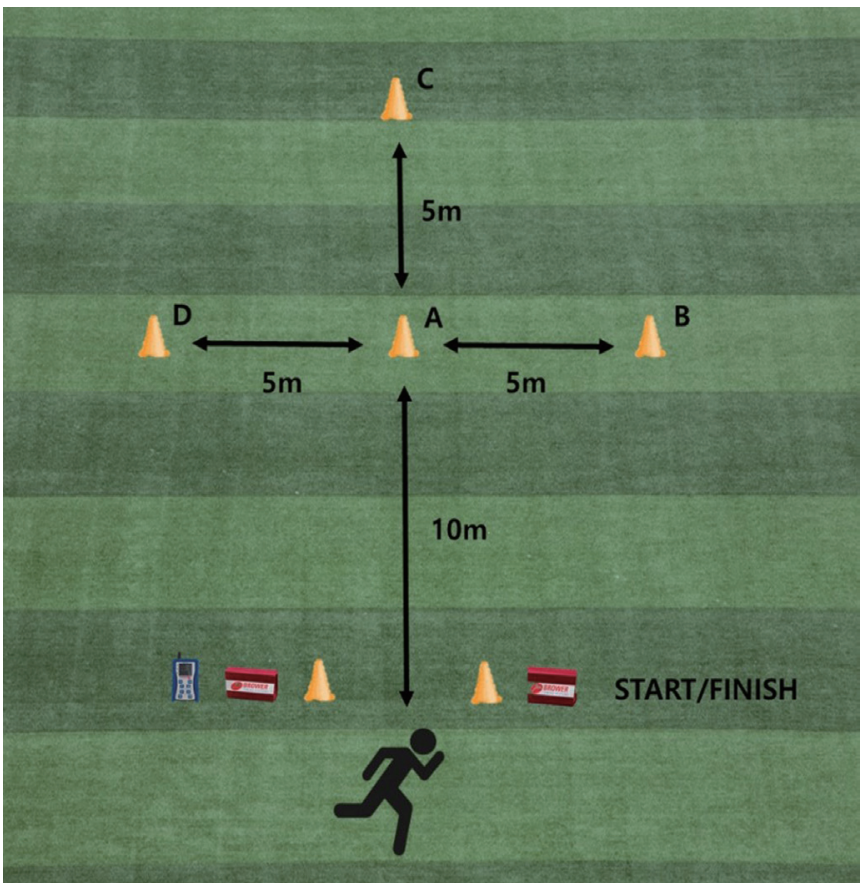

Fig. 2. Arrowhead agility test.

soccer athletes' agility [29]. The athlete stands at the start line and starts upon the investigator's cue. They run from the start line to cone A as quickly as possible, move to cone $\mathrm{B}$ on the side, circle around cone $\mathrm{C}$, and come back to the finish line as quickly as possible (Fig. 2). The same exercise was performed for the left and right sides.

\section{4) Yo-Yo IR test level 1}

The Yo-Yo IR test level 1 was performed based on the protocol suggested by Krustrup et al. [30]. Yo-Yo IR test level 1 consists of $20 \mathrm{~m}$ of running and $5 \mathrm{~m}$ of active recovery. The active recovery phase lasts 10 seconds. Colored cones are placed in each phase to help athletes focus on the test. They were given a cue through an audio system, and if they missed the cue for starting or finishing, one warning was given. If they missed the start or finish two times, they failed the test. All ten athletes participated in each test together.

\section{FMS}

The FMS consists of seven movement patterns (deep squat, hurdle step, in-line lunge, shoulder mobility, straight-leg raise, trunk stability push-up, and rotary stability) and three clearing tests (impingement, press-up, and posterior rocking) [16].

Participants' functional movements were measured using the tool shown in Fig. 3. The investigator gave a demonstration of the movement

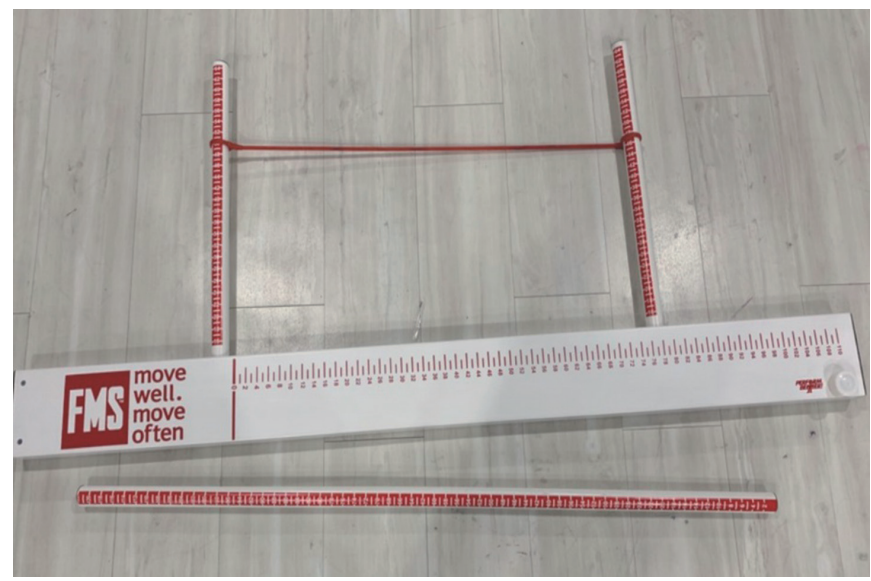

Fig. 3. Functional movement screen tool.

patterns. Then, the participants were instructed to perform the movement patterns, and they were scored based on the scoring criteria. We used the criteria for each movement pattern as shown in previous studies [20,31]. For example, the criteria for deep squat included "performed without a board," "hip break parallel," "lumbar flexion is not noted," and "feet do not externally rotate."

Each movement pattern was scored from 0-3, for a total score of 21. A score of 3 was given for ideal movement without compensation, a score of 2 for movement with compensation, and a score of 1 for inability to perform the movement. A score of 0 was given if there was pain during the movement pattern or clearing test $[18,32]$. The interrater (different raters reaching the same results; intraclass correlation coefficient $[\mathrm{ICC}]=0.89$ ) and intrarater reliabilities (same rater reaching the same results over several tests; ICC $=0.81-0.91$ ) of the FMS were high [33].

\section{Statistical Analysis}

Data were processed using the SPSS software (SPSS ver. 21.0, IBM Corp., NY, USA). All data were presented as mean \pm standard deviation (SD). The normality of the data distribution was confirmed with Levene's test. The time and group interaction effects were analyzed with repeated measure analysis of variance (ANOVA). Statistical significance was set at $p<.05$.

\section{RESULTS}

Changes in soccer-specific physical performance after the FIFA 11+ training program are shown in Table 3. In soccer-specific physical performance, there were significant time and group interaction effects for 
Table 3. Changes of soccer-specific physical performance after FIFA 11+ training program

\begin{tabular}{|c|c|c|c|c|}
\hline Variable & Group & Pre & Post & $p$ \\
\hline 10-m sprint (sec) & $\begin{array}{r}\text { FIFA 11+ training }(n=10) \\
\text { Control }(n=10)\end{array}$ & $\begin{array}{l}1.7 \pm 0.0 \\
1.7 \pm 0.0\end{array}$ & $\begin{array}{l}1.7 \pm 0.0 \\
1.7 \pm .0 .0\end{array}$ & .673 \\
\hline 30-m sprint (sec) & $\begin{array}{r}\text { FIFA } 11+\text { training }(n=10) \\
\text { Control }(n=10)\end{array}$ & $\begin{array}{l}4.2 \pm 0.1 \\
4.3 \pm 0.1\end{array}$ & $\begin{array}{l}4.1 \pm 0.0 \\
4.2 \pm 0.1\end{array}$ & $.027^{*}$ \\
\hline Coordination test (sec) & $\begin{array}{r}\text { FIFA } 11+\text { training }(n=10) \\
\text { Control }(n=10)\end{array}$ & $\begin{array}{l}17.3 \pm 1.3 \\
16.9 \pm 1.0\end{array}$ & $\begin{array}{l}16.8 \pm 1.3 \\
16.8 \pm 0.9\end{array}$ & $.021^{*}$ \\
\hline Arrowhead agility test (right, sec) & $\begin{array}{r}\text { FIFA } 11+\text { training }(n=10) \\
\text { Control }(n=10)\end{array}$ & $\begin{array}{l}9.0 \pm 0.2 \\
9.0 \pm 0.2\end{array}$ & $\begin{array}{l}8.8 \pm 0.3 \\
9.0 \pm 0.2\end{array}$ & $.009^{* *}$ \\
\hline Arrowhead agility test (left, sec) & $\begin{array}{r}\text { FIFA } 11+\text { training }(n=10) \\
\text { Control }(n=10)\end{array}$ & $\begin{array}{l}9.0 \pm 0.2 \\
8.9 \pm 0.4\end{array}$ & $\begin{array}{l}8.6 \pm 0.3 \\
9.0 \pm 0.3\end{array}$ & $.004^{* *}$ \\
\hline Yo-Yo IR test level 1 (m) & $\begin{array}{r}\text { FIFA } 11+\text { training }(n=10) \\
\text { Control }(n=10)\end{array}$ & $\begin{array}{l}2,496 \pm 204 \\
2,412 \pm 162\end{array}$ & $\begin{array}{l}2,484 \pm 225 \\
2,416 \pm 170\end{array}$ & .490 \\
\hline
\end{tabular}

Values are Mean \pm SD.

Yo-Yo IR test level 1, Yo-Yo intermittent recovery test level 1.

*Interaction effect between group and time $(p<.05)$; **Interaction effect between group and time $(p<.01)$, Tested by repeated measure analysis of variance.

Table 4. Changes of functional movement after FIFA 11+ training program

\begin{tabular}{|c|c|c|c|c|}
\hline Variable & Group & Pre & Post & $p$ \\
\hline Deep squat & $\begin{array}{r}\text { FIFA } 11+\text { training }(n=10) \\
\text { Control }(n=10)\end{array}$ & $\begin{array}{l}1.9 \pm 0.8 \\
1.6 \pm 0.5\end{array}$ & $\begin{array}{l}2.7 \pm 0.4 \\
1.7 \pm 0.6\end{array}$ & $.035^{*}$ \\
\hline Hurdle step & $\begin{array}{r}\text { FIFA } 11+\text { training }(n=10) \\
\text { Control }(n=10)\end{array}$ & $\begin{array}{l}1.6 \pm 0.6 \\
1.6 \pm 0.5\end{array}$ & $\begin{array}{l}2.4 \pm 0.5 \\
1.6 \pm 0.5\end{array}$ & $.005^{* *}$ \\
\hline In-line lunge & $\begin{array}{r}\text { FIFA } 11+\text { training }(n=10) \\
\text { Control }(n=10)\end{array}$ & $\begin{array}{l}2.2 \pm 0.7 \\
1.9 \pm 0.5\end{array}$ & $\begin{array}{l}2.3 \pm 0.4 \\
1.9 \pm 0.7\end{array}$ & .722 \\
\hline Shoulder mobility & $\begin{array}{r}\text { FIFA 11+ training }(n=10) \\
\text { Control }(n=10)\end{array}$ & $\begin{array}{l}1.7 \pm 1.1 \\
1.6 \pm 0.8\end{array}$ & $\begin{array}{l}1.9 \pm 0.9 \\
1.7 \pm 0.8\end{array}$ & .660 \\
\hline Straight-leg raise & $\begin{array}{r}\text { FIFA } 11+\text { training }(n=10) \\
\text { Control }(n=10)\end{array}$ & $\begin{array}{l}2.4 \pm 0.6 \\
2.4 \pm 0.5\end{array}$ & $\begin{array}{l}2.6 \pm 0.6 \\
2.3 \pm 0.4\end{array}$ & .279 \\
\hline Trunk stability push-up & $\begin{array}{r}\text { FIFA } 11+\text { training }(n=10) \\
\text { Control }(n=10)\end{array}$ & $\begin{array}{l}2.3 \pm 0.4 \\
2.3 \pm 0.6\end{array}$ & $\begin{array}{l}2.6 \pm 0.5 \\
2.5 \pm 0.5\end{array}$ & .628 \\
\hline Rotary stability & $\begin{array}{r}\text { FIFA 11+ training }(n=10) \\
\text { Control }(n=10)\end{array}$ & $\begin{array}{l}1.8 \pm 0.4 \\
1.8 \pm 0.4\end{array}$ & $\begin{array}{l}2.8 \pm 0.4 \\
2.0 \pm 0.6\end{array}$ & $.005^{* *}$ \\
\hline Total FMS score & $\begin{array}{r}\text { FIFA } 11+\text { training }(n=10) \\
\text { Control }(n=10)\end{array}$ & $\begin{array}{l}14.1 \pm 1.8 \\
13.3 \pm 1.2\end{array}$ & $\begin{array}{l}17.1 \pm 1.1 \\
13.8 \pm 1.2\end{array}$ & $.001^{* *}$ \\
\hline
\end{tabular}

Values are Mean \pm SD.

FMS, functional movement screen.

*Interaction effect between group and time $(p<.05)$; **Interaction effect between group and time $(p<.01)$; Tested by repeated measure analysis of variance.

the 30-m sprint $(p=.027)$, coordination test $(p=.021)$, and arrowhead agility test (right: $p=.009$, left: $p=.004$ ). However, there were no significant time and group interaction effects for the 10-m sprint and Yo-Yo IR test level $1(p>.05)$.

Changes in FMS after the FIFA 11+ training program are shown in Table 4. In the FMS, there were significant time and group interaction effects for the deep squat $(p=.035)$, hurdle step $(p=.005)$, rotary stability ( $p=.005)$, and total FMS score $(p=.001)$ but not for in-line lunge, shoulder mobility, straight-leg raise, and trunk stability push-up $(p>.05)$.

\section{DISCUSSION}

This study aimed to investigate the effects of a 12-week FIFA 11+ training program on soccer-specific physical performance and functional movement in collegiate male soccer players. The results showed that the FIFA 11+ training group showed improved 30-m sprint, coordination, and arrowhead agility (left and right) records with better functional movement, such as the deep squat, hurdle step, and rotary stability. These results are partially similar to the findings of Nawed et al. [10], who reported that a 12-week (5 sessions/week) FIFA 11+ training pro- 
gram significantly improved sprint speed in amateur male soccer players.

In soccer, sprinting is an important activity [34]. In particular, straight sprints repeatedly occur before scoring a goal [35], so performance of this movement may determine the outcome of the game. Sprinting fundamentally requires explosive power and speed of the lower limbs, and plyometric training is one of the most effective methods to boost these abilities [36]. Plyometric training is designed to help athletes utilize the elastic nature of the stretch-shortening cycle (SSC), and consists of exercises such as jumping, hopping, and bounding [37]. Part II of the FIFA $11+$ training program used in our study includes bounding or high-impact plyometric exercises performed in various planes, such as vertical jumps, lateral jumps, and box jumps. These exercises would have contributed to shortening the sprint record by increasing force and power of the athletes. A few recent studies reported that plyometric training is effective to improve sprint performance [38,39].

The Nordic hamstring curl in part II probably contributed to improving sprint records. The Nordic hamstring curl is an eccentric exercise that strengthens hamstrings eccentrically [40]. Because the hamstrings are maximally activated while sprinting [41], increased eccentric hamstring strength as a result of the Nordic hamstring curl can improve sprinting [42]. In fact, a cross-sectional study reported that eccentric hamstring strength is strongly correlated with sprint speed in soccer athletes [43].

In this study, we measured coordination by instructing participants to dribble through cones as quickly as possible, and arrowhead agility was measured while they quickly moved to the other direction after passing a cone. These movements require neuromuscular control, and soccer athletes must repeatedly perform closed skill activities (e.g. changing of direction and jumping), as well as open skills activities (e.g. balance) to improve this ability [44].

The exercises in the FIFA 11+ training program are based on leg strength, balance, dynamic postural control, knee control while cutting and landing, and joint range of motion related to neuromuscular control [45]. For example, exercises in the FIFA 11+ training program, such as running circling partner, running shoulder contact, running quick forwards and backwards, and running plant and cut, involve rapid decelerating, reversing, or changing direction of movement, and accelerating while redirecting $[9,22]$.

Therefore, continuous FIFA 11+ training could help athletes to perform complex movements, such as coordination and arrowhead agility, by improving their neuromuscular control. Similar to our findings, Barber-Westin et al. [46] reported that regularly applying a neuromuscular training program that includes dynamic balance, agility, and strength significantly improved tennis-specific drills in tennis players. The changes of FMS scores in the FIFA 11+ training group support our hypothesis regarding improvement of neuromuscular control after training, as movement patterns included in the FMS require neuromuscular/motor control [47]. Particularly, the hurdle step, which is one of the movement patterns, requires proper coordination because it is designed to assess the body's stride mechanism that occurs during the stepping motion [16].

In addition, core exercises such as the bench and sideways bench in the FIFA 11+ training program could have contributed to enhanced soccer-specific physical performance and functional movement. In the present study, functional movements that showed significant changes in the score after training included the deep squat, hurdle step, and rotary stability. These movement patterns assess core stability [16]. Core stability is defined as dynamic trunk control that can produce, transfer, and control force and motion in the distal segments of the kinetic chain, including the trunk and pelvis muscles [48].

On the other hand, reduced muscular synergy and poor core stability of the trunk and pelvis stabilizers diminish performance and limits the control of the center of mass; thereby, increasing the risk for injury [49]. Some studies reported that core training can significantly improve sprints [50] and agility [51], and Nesser et al. [52] reported that core stability in football players is significantly associated with sprint performance. Furthermore, it has also been reported that athletes with good functional movement patterns (high-scoring group) showed superior sprint and agility records [53].

This study has a few limitations. First, our sample size was small. In the future, more participants should be recruited. Second, the FIFA 11+ training is well-known to be associated with injury prevention [22,25]. However, we only observed changes of performance or movement caused by FIFA 11+ training and did not investigate how much these changes contributed to injury prevention among the athletes. Finally, our study hypotheses described in the discussion section were only explained based on previous research findings, and not on measurements taken in this study. For instance, we could not examine whether biomechanical factors related to neuromuscular control actually changed after the FIFA 11+ training. Moreover, eccentric hamstring strength, which we speculate contributed to improved sprint records, was not measured 
in our study. Subsequent studies should address these shortcomings and examine other additional parameters.

\section{CONCLUSION}

In conclusion, a 12-week FIFA 11+ training program had positive effects on physical performance and functional movement in collegiate male soccer players. Thus, we recommend coaches and trainers to actively utilize the FIFA 11+ training program as a pre-game warm-up or during physical training sessions.

\section{CONFLICT OF INTEREST}

No potential conflict of interest relevant to this article was reported.

\section{REFERENCES}

1. Bizzini M, Junge A, Dvorak J. Implementation of the FIFA 11+ football warm up program: how to approach and convince the Football associations to invest in prevention. Br J Sports Med. 2013;47(12):8036.

2. Di Salvo V, Baron R, Tschan H, Calderon Montero FJ, Bachl N, et al. Performance characteristics according to playing position in elite soccer. Int J Sports Med. 2007;28(3):222-7.

3. Boone J, Vaeyens R, Steyaert A, Vanden Bossche L, Bourgois J. Physical fitness of elite Belgian soccer players by player position. J Strength Cond Res. 2012;26(8):2051-7.

4. Howard N, Stavrianeas S. In-season high-intensity interval training improves conditioning in high school soccer players. Int J Exerc Sci. 2017;10(5):713-20.

5. de Hoyo M, Pozzo M, Sañudo B, Carrasco L, Gonzalo-Skok O, et al. Effects of a 10-week in-season eccentric-overload training program on muscle-injury prevention and performance in junior elite soccer players. Int J Sports Physiol Perform. 2015;10(1):46-52.

6. Orhant E, Carling C, Cox A. A three-year prospective study of illness in professional soccer players. Res Sports Med. 2010;18(3):199-204.

7. Sadigursky D, Braid JA, De Lira DNL, Machado BAB, Carneiro RJF, et al. The FIFA 11+ injury prevention program for soccer players: a systematic review. BMC Sports Sci Med Rehabil. 2017;9:18.

8. Soligard T, Myklebust G, Steffen K, Holme I, Silvers H, et al. Comprehensive warm-up programme to prevent injuries in young female footballers: cluster randomised controlled trial. BMJ. 2008;337:a2469.

9. Barengo NC, Meneses-Echávez JF, Ramírez-Vélez R, Cohen DD, Tovar G, et al. The impact of the FIFA 11+ training program on injury prevention in football players: a systematic review. Int J Environ Res Public Health. 2014;11(11):11986-2000.

10. Nawed A, Khan IA, Jalwan J, Nuhmani S, Muaidi QI. Efficacy of FIFA $11+$ training program on functional performance in amateur male soccer players. J Back Musculoskelet Rehabil. 2018;31(5):867-70.

11. Owoeye OBA, Palacios-Derflingher LM, Emery CA. Prevention of ankle sprain injuries in youth soccer and basketball: effectiveness of a neuromuscular training program and examining risk factors. Clin J Sport Med. 2018;28(4):325-31.

12. Rodríguez C, Echegoyen S, Aoyama T. The effects of "prevent injury and enhance performance program" in a female soccer team. J Sports Med Phys Fitness. 2018;58(5):659-63.

13. Huxel Bliven $\mathrm{KC}$, Anderson BE. Core stability training for injury prevention. Sports Health. 2013;5(6):514-22.

14. Whyte EF, Richter C, O'Connor S, Moran KA. Effects of a dynamic core stability program on the biomechanics of cutting maneuvers: a randomized controlled trial. Scand J Med Sci Sports. 2018;28(2):45262.

15. Wingfield K. Neuromuscular training to prevent knee injuries in adolescent female soccer players. Clin J Sport Med. 2013;23(5):407-8.

16. Cook G, Burton L, Hoogenboom BJ, Voight M. Functional movement screening: the use of fundamental movements as an assessment of function - part 1. Int J Sports Phys Ther. 2014;9(3):396-409.

17. Kiesel K, Plisky PJ, Voight ML. Can serious injury in professional football be predicted by a preseason functional movement screen? N Am J Sports Phys Ther. 2007;2(3):147-58.

18. Dorrel BS, Long T, Shaffer S, Myer GD. Evaluation of the functional movement screen as an injury prediction tool among active adult populations: a systematic review and meta-analysis. Sports Health. 2015;7(6):532-7.

19. Hotta T, Nishiguchi S, Fukutani N, Tashiro Y, Adachi D, et al. Functional movement screen for predicting running injuries in 18 - to 24-year-old competitive male runners. J Strength Cond Res. 2015; 29(10):2808-15.

20. Cook G, Burton L, Hoogenboom B. Pre-participation screening: the use of fundamental movements as an assessment of function - part 1. N Am J Sports Phys Ther. 2006;1(2):62-72.

21. Silva B, Clemente FM, Martins FM. Associations between functional 
movement screen scores and performance variables in surf athletes. J Sports Med Phys Fitness. 2018;58(5):583-90.

22. Al Attar WSA, Soomro N, Pappas E, Sinclair PJ, Sanders RH. Adding a post-training FIFA 11+ exercise program to the pre-training FIFA $11+$ injury prevention program reduces injury rates among male amateur soccer players: a cluster-randomised trial. J Physiother. 2017; 63(4):235-42.

23. Grooms DR, Palmer T, Onate JA, Myer GD, Grindstaff T. Soccer-specific warm-up and lower extremity injury rates in collegiate male soccer players. J Athl Train. 2013;48(6):782-9.

24. Silvers-Granelli HJ, Bizzini M, Arundale A, Mandelbaum BR, SnyderMackler L. Does the FIFA 11+ injury prevention program reduce the incidence of ACL injury in male soccer players? Clin Orthop Relat Res. 2017;475(10):2447-55.

25. Thorborg K, Krommes KK, Esteve E, Clausen MB, Bartels EM, et al. Effect of specific exercise-based football injury prevention programmes on the overall injury rate in football: a systematic review and meta-analysis of the FIFA 11 and 11+ programmes. Br J Sports Med. 2017;51(7):562-71.

26. Daneshjoo A, Mokhtar AH, Rahnama N, Yusof A. The effects of injury preventive warm-up programs on knee strength ratio in young male professional soccer players. PLoS One. 2012;7(12):e50979.

27. Joo $\mathrm{CH}$. The effects of short term detraining and retraining on physical fitness in elite soccer players. PLoS One. 2018;13(5):0196212.

28. Joo $\mathrm{CH}$. The effects of short-term detraining on exercise performance in soccer players. J Exerc Rehabil. 2016;12(1):54-9.

29. Noon MR, James RS, Clarke ND, Akubat I, Thake CD. Perceptions of well-being and physical performance in English elite youth footballers across a season. J Sports Sci. 2015;33(20):2106-15.

30. Krustrup P, Mohr M, Amstrup T, Rysgaard T, Johansen J, et al. The yo-yo intermittent recovery test: physiological response, reliability, and validity. Med Sci Sports Exerc. 2003;35(4):697-705.

31. Frost DM, Beach TA, Callaghan JP, McGill SM. Using the functional movement screen ${ }^{\mathrm{TM}}$ to evaluate the effectiveness of training. J Strength Cond Res. 2012;26(6):1620-30.

32. O'Connor FG, Deuster PA, Davis J, Pappas CG, Knapik JJ. Functional movement screening: predicting injuries in officer candidates. Med Sci Sports Exerc. 2011;43(12):2224-30.

33. Smith CA, Chimera NJ, Wright NJ, Warren M. Interrater and intrarater reliability of the functional movement screen. J Strength Cond Res. 2013;27(4):982-7.
34. Andrzejewski M, Chmura J, Pluta B, Strzelczyk R, Kasprzak A. Analysis of sprinting activities of professional soccer players. J Strength Cond Res. 2013;27(8):2134-40.

35. Haugen T, Tønnessen E, Hisdal J, Seiler S. The role and development of sprinting speed in soccer. Int J Sports Physiol Perform. 2014;9(3): $432-41$.

36. Ozbar N, Ates S, Agopyan A. The effect of 8-week plyometric training on leg power, jump and sprint performance in female soccer players. J Strength Cond Res. 2014;28(10):2888-94.

37. Singh J, Appleby BB, Lavender AP. Effect of plyometric training on speed and change of direction ability in elite field hockey players. Sports. 2018;6(4):E144.

38. Beato M, Bianchi M, Coratella G, Merlini M, Drust B. Effects of plyometric and directional training on speed and jump performance in elite youth soccer players. J Strength Cond Res. 2018;32(2):289-96.

39. Hammami M, Gaamouri N, Aloui G, Shephard RJ, Chelly MS. Effects of combined plyometric and short sprint with change-of-direction training on athletic performance of male U15 handball players. J Strength Cond Res. 2019;33(3):662-75.

40. Petersen J, Thorborg K, Nielsen MB, Budtz-Jørgensen E, Hölmich P. Preventive effect of eccentric training on acute hamstring injuries in men's soccer: a cluster-randomized controlled trial. Am J Sports Med. 2011;39(11):2296-303.

41. Yu B, Queen RM, Abbey AN, Liu Y, Moorman CT, et al. Hamstring muscle kinematics and activation during overground sprinting. J Biomech. 2008;41(15):3121-6.

42. Ishøi L, Hölmich P, Aagaard P, Thorborg K, Bandholm T, et al. Effects of the nordic hamstring exercise on sprint capacity in male football players: a randomized controlled trial. J Sports Sci. 2018;36(14):166372.

43. Markovic G, Sarabon N, Boban F, Zoric I, Jelcic M, et al. Nordic hamstring strength of highly trained youth football players and its relation to sprint performance. J Strength Cond Res. 2018.

44. Gabbett TJ, Sheppard JM, Pritchard-Peschek KR, Leveritt MD, Aldred MJ. Influence of closed skill and open skill warm-ups on the performance of speed, change of direction speed, vertical jump, and reactive agility in team sport athletes. J Strength Cond Res. 2008;22(5):1413-5.

45. Kiani A, Hellquist E, Ahlqvist K, Gedeborg R, Michaëlsson K, et al. Prevention of soccer-related knee injuries in teenaged girls. Arch Intern Med. 2010;170(1):43-9.

46. Barber-Westin SD, Hermeto AA, Noyes FR. A six-week neuromuscu- 
lar training program for competitive junior tennis players. J Strength Cond Res. 2010;24(9):2372-82.

47. Tafuri S, Notarnicola A, Monno A, Ferretti F, Moretti B. CrossFit athletes exhibit high symmetry of fundamental movement patterns. A cross-sectional study. Muscles Ligaments Tendons J. 2016;6(1):157-60.

48. Kibler WB, Press J, Sciascia A. The role of core stability in athletic function. Sports Med. 2006;36(3):189-98.

49. Hewett TE, Zazulak BT, Myer GD, Ford KR. A review of electromyographic activation levels, timing differences, and increased anterior cruciate ligament injury incidence in female athletes. Br J Sports Med. 2005;39(6):347-50.

50. Prieske O, Muehlbauer T, Borde R, Gube M, Bruhn S, et al. Neuromuscular and athletic performance following core strength training in elite youth soccer: Role of instability. Scand J Med Sci Sports. 2016;26(1):48-56.

51. Bashir SF, Nuhmani S, Dhall R, Muaidi QI. Effect of core training on dynamic balance and agility among Indian junior tennis players. J Back Musculoskelet Rehabil. 2018.

52. Nesser TW, Huxel KC, Tincher JL, Okada T. The relationship between core stability and performance in division I football players. J Strength Cond Res. 2008;22(6):1750-4.

53. Liang YP, Kuo YL, Hsu HC, Hsia YY, Hsu YW, et al. Collegiate baseball players with more optimal functional movement patterns demonstrate better athletic performance in speed and agility. J Sports Sci. 2019;37(5):544-52. 